\title{
SOBRE UNA SERIE ICÓNICA DE TRASTÁMARAS Y HABSBURGOS EN UN INSÓLITO CUADRO DE ALTAR DE LA NOBLEZA ANDALUZA
}

\author{
ABOUT AN ICONIC SERIES OF TRASTÁMARAS AND \\ HABSBURGS IN AN UNUSUAL ALTARPIECE PAINTING \\ OF AN ANDALUSIAN ARISTOCRATIC FAMILY
}

\author{
FERNANDO CRUZ IsIDORO \\ Universidad de Sevilla. España \\ cruzisidoro@us.es
}

\begin{abstract}
Se identifican los componentes de una serie icónica de Trastámaras y Habsburgos, junto a familiares de los Guzmanes, que completa la iconografía de un peculiar cuadro de altar que encargó el VII duque de Medina Sidonia Alonso Pérez de Guzmán (1549-1615). Fue concebido como signo de representación de la casa aristocrática, de gran peso en Andalucía occidental, apropiándose de signos del poder real para vincular su propia historia con la del Estado hispano.

Palabras clave: Trastámara; Habsburgo; duque de Medina Sidonia; pintura; Sanlúcar de Barrameda.

This paper identifies the components of an iconic series of Trastámaras and Habsburgs, together with those of the family of the Guzmanes, which completes the iconography of a peculiar altarpiece painting commissioned by the VII Duke of Medina Sidonia Alonso Pérez de Guzmán (1549-1615). It was conceived as a sign of representation of this aristocratic family, of great weight in Western Andalusia, appropriating signs of royal power to link its own family history with that of the Hispanic State.

Keywords: Trastámara; Habsburg; Duke of Medina Sidonia; painting; Sanlúcar de Barrameda.
\end{abstract}

Aunque sobre este cuadro ya hemos tratado en varias ocasiones, documentando autor, fecha, coste material e iconografía, que pusimos en relación con el resto de la producción del pintor y la programación iconográfica del edificio, que fue concebido como santuario mariano y panteón funerario del VII duque de 
Medina Sidonia ${ }^{1}$, y que la profesora Lina Malo (q.e.p.d), a la que se dedica este volumen, posteriormente estudió los problemas que su controvertida temática provocó en el siglo XVIII ${ }^{2}$, todavía quedaba por identificar la serie completa de los personajes civiles representados. Creímos que la elección del tema, donde ambos coincidimos, era apropiada para la ocasión, y originales los objetivos marcados. La restauración realizada en el cuadro nos permitía acceder a las leyendas de los personajes y al análisis de su fisonomía, y con ello, al mensaje narrado en su integridad. Además, había que identificar las posibles fuentes utilizadas, literarias y formales, y el por qué del uso de la serie icónica de la Casa Real en beneficio de esta familia.

Lo singular del cuadro que tratamos, donde se representa la serie de Trastámaras y Habsburgos, radica en el contexto para el que se realiza, integrada en un cuadro de altar de un edificio de patronazgo señorial, que fue concebido como signo de representación de una familia aristocrática del sur, la de los Guzmán, y no, como cabría esperar, formando parte de la galería de retratos de un inmueble real o, en alguna de sus fundaciones religiosas - conventos de las Descalzas Reales y de la Encarnación de Madrid, monasterio de San Lorenzo de El Escorial o las Huelgas Reales de Burgos-. Podemos verla en la Genealogía de los Guzmanes, que costeó en 1612 el VII duque de Medina Sidonia, Alonso Pérez de Guzmán el Bueno (1549-1615), para el santuario mariano, actual basílica menor, de Nuestra Señora de la Caridad, en Sanlúcar de Barrameda (Cádiz), capital de su estado señorial. Se ideó para formar pareja con una Genealogía de Cristo y para un lugar preferencial, la cabecera del templo, buscando un difícil parangón con el Mesías que provocó más de un problema con la autoridad eclesiástica sevillana tras la pérdida del señorío sobre la ciudad, pero que sigue estando al culto (Figura 1).

El óleo sobre lienzo, de 342 x $240 \mathrm{~cm}$, lo pintó el maestro ducal florentino Francisco Juanete ${ }^{3}$, así llamado en la documentación pero que firmaba Ginete.

${ }^{1}$ CRUZ ISIDORO, Fernando: "Francisco Juanete, pintor de cámara de la Casa ducal de Medina Sidonia (1604-1638)", Laboratorio de Arte, 11, 1998, pp. 439-440; CRUZ ISIDORO, Fernando: "El programa iconográfico del Santuario de Ntra. Sra. de la Caridad, de Sanlúcar de Barrameda", en V Simposio Bíblico Español. La Biblia en el Arte y en la Literatura. T. II. Valencia-Pamplona, 1999, pp. 401-416; y CRUZ ISIDORO, Fernando: "Un cuadro de altar de trasfondo ideológico: la Genealogía de los Guzmanes, del pintor barroco Francisco Juanete (1612)", Archivo Español de Arte, LXXVIII, 2005, pp. 427-434.

${ }^{2}$ MALO LARA, Lina: "Conflictos de poder: patronos, retratos y retablos del barroco. La Genealogía de los Guzmanes de la Casa de Medina Sidonia”, en Arte, poder y sociedad. Y otros estudios sobre Extremadura. Llerena, 2006, pp. 95-108.

${ }^{3}$ La identificación de su procedencia italiana se la debemos a Antonio Romero Dorado (Grupo de Investigación HUM-171), que advirtió que era el pintor Francisco Yaneti según se recoge en ÁLVAREZ Y BAENA, José Antonio: Hijos de Madrid: ilustres en santidad, dignidad, armas, ciencias y artes. Diccionario histórico por el orden alfabético de sus nombres, que consagra el illmo. y nobilísimo ayuntamiento de la imperial y coronada villa de Madrid. T. III, 
Lo contrató el 4 de enero de 1612 junto con la Genealogía de Cristo y otros cuadros por la suma total de 4.000 reales, así valorados por los pintores Francisco Núñez de Prado y Diego de Esquivel, y conclusos para el 20 de octubre ${ }^{4}$. Su autor, "maestro pintor de imaginería", del que establecimos biografía, estilo y catálogo profesional $^{5}$, desempeñó la plaza de pintor de cámara de la Casa a las órdenes del conde de Niebla don Manuel, que era el primogénito, y de su padre el VII duque ${ }^{6}$. También residió en Madrid, donde retrató a Lope de Vega en 1625, y, dos años más tarde, fue pintor de cámara por dos veces de su alteza el cardenal don Fernando. Allí recibió por aprendiz a Ramón Michelet y se defendió del pago de la alcabala $^{7}$. Su estilo osciló entre los resabios manieristas de la escuela sevillana de esos momentos, en la línea del portugués Vasco Pereira, con el que pudo formarse y colaboró, y las formas naturalistas del flamenco Juan de Roelas.

Creemos que el creador iconográfico y del mensaje subliminal fue el presbítero y licenciado Diego López de Soria, administrador del santuario y capellán mayor de su Junta, quizás en colaboración con alguno de sus miembros y, con seguridad, con el poeta dominico fray Pedro Beltrán (1570-1663), estante por entonces en el convento de Santo Domingo de la ciudad y autor del poema $L a$ Charidad Guzmana $(1612)^{8}$, dado el exacto conocimiento de la iconografía de esa orden. Juanete ya había representado con antelación el tema, por lo que estamos ante un programa iconográfico consolidado, pues la primera obra que le docu-

Madrid, 1790, pp. 362-363, donde afirma cómo realizó un retrato de Lope de Vega "que se dexó copiar del pincel de Francisco Yaneti, Florentin, segun refiere en la Dedicatoria que hizo al mismo Caballero Marino, de la Comedia, Virtud, pobreza y muger".

${ }^{4}$ CRUZ ISIDORO, Fernando: "Francisco Juanete...", op. cit, pp. 435-459.

${ }^{5}$ CRUZ ISIDORO, Fernando: El Santuario de Ntra. Sra. de la Caridad de Sanlúcar de Barrameda. Estudio Histórico-Artístico. Córdoba, 1997, pp. 435-459; CRUZ ISIDORO, Fernando: "Francisco Juanete...", op. cit, pp. 435-459; y CRUZ ISIDORO, Fernando: El patrimonio restaurado de la Basílica de la Caridad de Sanlúcar de Barrameda. Sanlúcar de Barrameda, 2011, pp. 82-102.

${ }^{6}$ Tuvo ración alimenticia, probablemente cama, y un salario anual de 22.500 maravedíes (unos 2 reales diarios), y ayudas de costa en especie. VELÁZQUEZ GAZTELU, Juan Pedro: Catálogo de todas las Personas Ilustres y Notables de esta ciudad de Sanlúcar de Barrameda. Desde la mayor antigüedad que se ha podido encontrar en lo escrito hasta este año de 1760. Introd., transcrip. y edición de Fernando Cruz Isidoro. Sanlúcar de Barrameda, 1996, pp. 204 y 269.

7 Noticias recogidas por DELGADO LÓPEZ, Félix: "Juan de Baeza y las pinturas de Vicente Carducho en la cartuja del Paular”, Locus Amoenus, 4, 1998-1999, p. 187, nota 9; PORTÚS PÉREZ, Javier: Lope de Vega y las Artes Plásticas, estudio sobre las relaciones entre pintura y poesía en la España del siglo de oro. Madrid, 1992, pp. 262-263; AGULLÓ COBO, Mercedes: Noticias sobre pintores madrileños de los siglos XVI y XVII. Granada, 1978, p. 181; y MATILLA TASCÓN, Antonio: "Comercio de pintura y alcabalas", Goya, 178, 1984, pp.180-181.

${ }^{8}$ Biblioteca Nacional de España, Manuscrito/188. 
mentamos resulta un "lienzo de la ystoria de la Casa de Guzmán”, nueve años anterior y no localizada, que le encargó la condesa de Niebla Juana Lorenza, esposa de don Manuel, y en la que se encontraba trabajando en julio de $1603^{\circ}$. Ahora dispondrá en la mitad izquierda del cuadro a santos, beatos, venerables y papas de la orden dominica, y en la derecha a los laicos que prestigiaron la estirpe familiar, pero lo extraño es que la mayoría son miembros de las Casas de Trastámara y Habsburgo, consideradas cercanas o incluso propias. Para esa operación de acomodo, el iconógrafo utiliza como nexo de unión la relación extramatrimonial de Alfonso XI el Justiciero con una Guzmán, doña Leonor, cuya descendencia originó una nueva dinastía, la de los Trastámaras, castellanos y aragoneses, que por línea directa devino en los Habsburgos hispanos, de ahí su parentesco familiar con la realeza y la excusa para usar su imagen y la de otros poderosos europeos.

Es sabido que el empleo de retratos por el poder real viene de antiguo, pues la idea de que su autoridad emana de la divinidad determinó que, desde la Edad Media, la monarquía quisiera ser representada conforme a modelos preestablecidos. El posible origen iconográfico se ha buscado en los retratos imperiales romanos y en los ciclos de pontífices y prelados que, tras establecerse en la sede diocesana, mostraban así la genealogía espiritual que los avalaba aunque, verdaderamente, la tipología parece cristalizar con las disposiciones que estableció Alfonso X el Sabio, a mediados del siglo XIII, en el Especulo (libro II, título XIII), al dictar normas sobre el uso de la imagen de la monarquía, que derivaron en la creación de las primeras galerías de retratos reales para los espacios oficiales de aparato o de ostentación en las residencias regias, como eran los salones del trono de los alcázares ${ }^{10}$. Al principio eran series icónicas o dinásticas que buscaban el carácter genealógico e histórico, sin requerir una imagen verdadera, aludiendo a símbolos y emblemas perfectamente reconocibles, transmisores de autoridad y prestigio, de legitimidad y continuidad de la estirpe reinante, y luego introdujeron ciertos rasgos fisonómicos de sus componentes, puestos de moda por el retrato privado flamenco y desarrolladas durante el Renacimiento y el Barroco, aunque siempre manipuladas para reflejar la dignidad y la autoridad moral que debían primar sobre la apariencia física. Ambas tipologías cuentan con estudios pioneros para el caso hispano, como fueron, respectivamente, los de Elías Tormo y Sánchez Cantón ${ }^{11}$, que han originado una larga secuela en su investigación e im-

${ }^{9}$ CRUZ ISIDORO, Fernando: El patrimonio restaurado de la Basílica de la Caridad..., op. cit., pp. 84-85.

${ }^{10}$ CASTILlO OREJA, Miguel Ángel: "Imagen del rey, símbolos de la monarquía y divisas de los reinos: de las series de linajes de la Baja Edad Media a las galerías de retratos del Renacimiento", en Galería de Reyes y Damas del Salón de Embajadores. Obras maestras restauradas. Madrid, 2002, pp. 11-13.

11 TORMO Y MONZÓ, Elías: Las viejas series icónicas de los Reyes de España. Madrid, 1917; y SÁNCHEZ CANTÓN, Francisco Javier: Los retratos de los Reyes de España. 
portantes exposiciones al respecto, como la celebrada entre diciembre de 2014 y abril de 2015, El Retrato en las colecciones reales de Patrimonio Nacional: de Juan de Flandes a Antonio López ${ }^{12}$.

Una imagen del poder que se intentó controlar más estrechamente desde Felipe II, al crear nuevas galerías de retratos reales en el palacio de El Pardo, el Alcázar de Madrid y el monasterio de El Escorial ${ }^{13}$, donde se concreta la representación de aparato que tendría vigencia en el futuro, al exaltar las virtudes de majestad, provocando, a pesar de su concreción como verdadero retrato, un cierto distanciamiento aristocrático en el modelo, en un difícil equilibrio entre la imitatio y el decorum, que a veces roza en el icono como en algunos retratos de Sánchez Coello y, fundamentalmente, en los de Pantoja de la Cruz. Sin olvidar la conservación y ampliación que de las viejas series icónicas de Segovia y Sevilla se realizaron, pues seguían conservando su validez ${ }^{14}$. En esa estela, la aristocracia emulará el proceder, usando para prestigiar su estirpe avales como las series de "hombres ilustres" de la Antigüedad, que auspiciara el humanismo italiano, que incorporará al programa decorativo de algunas de sus residencias ${ }^{15}$, y que devino en ocasiones en galerías de retratos del comitente y familiares, que recogiesen los

\section{Barcelona, 1948.}

${ }^{12}$ Véanse las síntesis FALOMIR, Miguel: "Los orígenes del retrato en España. De la falta de especialista al gran taller", en El retrato español. Del Greco a Picasso, Madrid, 2005, pp. 68-83; y RUIZ GÓMEZ, Leticia: "Retratos de corte en la monarquía española (1530-1660)", en El retrato español. Del Greco a Picasso, Madrid, 2005, pp. 92-109. Véase también GARCÍA-FRÍAS CHECA, Carmen: "El retrato en las colecciones reales de Patrimonio Nacional: de la Casa de Trastámara a la Casa de Austria", en El Retrato en las colecciones reales de Patrimonio Nacional. De Juan de Flandes a Antonio López. Madrid, 2014, pp. 94-257.

13 CASTILLO OREJA, Miguel Ángel: "Imagen del rey, símbolos de la monarquía...", op. cit., pp. 13-19, 23-25 y 27-32.

${ }^{14}$ SERRERA, Juan Miguel: "Alonso Sánchez Coello y la mecánica del retrato de corte", en Alonso Sánchez Coello y el retrato en la corte de Felipe II. Madrid, 1990, pp. 3763; FALOMIR FAUS, Miguel: "Imágenes de poder y evocaciones de la memoria. Usos y funciones del retrato en la corte de Felipe II", en Un príncipe del Renacimiento: Felipe II, un monarca y su época. Madrid, 1998, pp. 203-227; y GARCÍA-FRÍAS CHECA, Carmen: "El retrato en las colecciones reales de Patrimonio Nacional: de la Casa de Trastámara a la Casa de Austria...", op. cit., pp. 94-121.

${ }^{15}$ Como en las galerías altas del patio principal del palacio sevillano de Pilatos, que encargó en 1539 el marqués de Tarifa don Fadrique Enríquez de Ribera, inspirada en los uomini famosi de Petrarca, disponiéndose junto a Homero, Virgilio y Horacio unos árboles genealógicos del linaje, hoy perdidos, que parecían demostrar los orígenes míticos de los Enríquez, como descendientes de Hércules. LLEÓ CAÑAL, Vicente: Nueva Roma. Mitología y humanismo en el Renacimiento sevillano, Madrid, 2012, pp. 55-57; y LLEÓ CAÑAL, Vicente: La Casa de Pilatos. Madrid, 1998, pp. 29-30. 
hechos heroicos y de fama que enalteciesen su abolengo, a veces apropiándose de iconografías míticas ${ }^{16}$.

En la adopción de la serie icónica real por el cuadro sanluqueño, tuvo que pesar el uso de la Valeriana o Crónica abreviada de España, escrita por el caballero conquense mosén Diego de Valera entre 1479 y 1481, que es la primera crónica que se publicó en Castilla, editada en Sevilla en 1482 por orden de Isabel la Católica, muy ligada al convulso proceso político de formación del Estado moderno en España de esos años, al servir de apoyo histórico para asegurar el trono y la estabilidad, pues sus páginas defienden la primacía de Castilla y la legitimidad de la dinastía, por tanto, una pieza más de la propaganda usada por la monarquía para difundir su discurso político, ligada al fin de la guerra de Portugal, la unión dinástica con la corona de Aragón y la guerra de Granada ${ }^{17}$. Su vinculación con los Guzmanes, aparte de por su actividad cortesana y acción política, podría hallarse en la posible redacción de la Coronica, Ystoria antigua o Ystoria vieja de la Casa de Guzmán, que se le ha atribuido desde que Lucas de Torre y Franco-Romero publicara en 1914 un extensísimo artículo sobre su vida y producción histórica, pues junto a la Historia de la Casa de Zúñiga, le adscribió ese texto sobre los orígenes de los Guzmanes andaluces, del que se conservan varias copias, entre otras en la Biblioteca Nacional ${ }^{18}$. Similar parecer mantiene Ladero Quesada ${ }^{19}$, pero, recientemente, Juan Luis Carriazo ha matizado esa consideración al creer distintas la conservada en el monasterio de San Isidoro de Sevilla, una biografía caballeresca muy cercana al fundador de la dinastía, don Alonso Pérez de Guzmán el Bueno, I señor de Sanlúcar de Barrameda, que debió ser compuesta por el propio abad antes de 1322, en vida de su viuda doña María Alonso Coronel, y la que pudo redactar Valera, el Origen de la Casa de Guzmán, citada con cierto desprecio como "librillo viejo" por el cronista Barrantes Maldonado, y que se conservaba en el

${ }^{16}$ Como en el palacio del I marqués de Santa Cruz en El Viso. DEL CAMPO MUÑOZ, Juan y DOLAREA CALVAR, Ricardo: Palacio del Viso del Marqués. Madrid, 2003, pp. 24, 40 y 47-53.

${ }_{17}$ Gran conocedor del mundo caballeresco y genealógico, en su redacción tuvo en cuenta, junto a la Estoria del fecho de los godos, atribuida al arzobispo don Rodrigo Jiménez de Rada, y la Crónica de 1344 de Alonso de Cartagena, los acontecimientos vividos personalmente al servicio de tres monarcas: Juan II, Enrique IV e Isabel I. Desempeñó un destacado papel como consejero y diplomático de esa reina, permitiendo la protección de la corona el que se publicasen veinte ediciones de su Valeriana entre 1482 y 1567. MOYA GARCÍA, Cristina: Edición y estudio de la "Valeriana" ("Crónica abreviada de España" de Mosén Diego de Valera). Madrid, 2009, pp. XV-XVI, XXI-XXIII, XXXV, XXXVIII, XL, XVVIII, LV, LXI, LXV y LXX.

${ }^{18}$ DE TORRE Y FRANCO-ROMERO, Lucas: "Mosén Diego de Valera: su vida y obras", Boletín de la Real Academia de la Historia. Informes, LXIV-II, 1914, pp. 9-168.

${ }^{19}$ LADERO QUESADA, Miguel Ángel: Guzmán. La Casa ducal de Medina Sidonia en Sevilla y su reino (1282-1521). Madrid, 2015, pp. 499-519. 
palacio sanluqueño ${ }^{20}$. De una manera u otra, ambos textos debieron ser empleados por iconógrafo y pintor para La Genealogía de los Guzmanes, al considerar la dinastía de origen bretón ${ }^{21}$, pero también lo fueron otras crónicas que dieron forma a la historia oficial de la Casa durante el siglo XVI, como las Ilustraciones de la Casa de Niebla de Pedro Barrantes Maldonado (1510-c.1580), conclusas en 1541, por mandato del VI duque don Juan Alonso de Guzmán, y que completara Pedro de Medina (c.1493-c.1567) con la Crónica de 1561. Este cosmógrafo se encargó de la formación intelectual del VII duque de Medina Sidonia, como su maestro o mentor, conservándose libranza ducal de 50 ducados en 1560 por una “descripción de la progenie y estado" de los Guzmanes, 40 ducados por recoger los pasajes más ilustres de la historia familiar, o 25.000 maravedíes por hacerlos extensibles a todos "los hechos notables, que en servicio destos reinos hicieron los señores destos estados"22. A esos textos se sumarían otros de alabanza, como los del dominico fray Pedro Beltrán, con su Charidad guzmana, largo poema escrito en 1612 al calor de los acontecimientos vividos con la imagen de Nuestra Señora de la Caridad, elegida por el duque para velar su eterno sueño y que, años más tarde, en septiembre de 1618, su hijo don Manuel elevaría a patrona de la Casa ducal y de todos sus estados territoriales, o los textos laudatorios del rector del colegio de San Ildefonso, el excelso poeta antequerano Pedro de Espinosa ${ }^{23}$.

Junto a estos componentes histórico-míticos, se añadirían los formales-artísticos para la concreción de tan peculiar iconografía y, particularmente, en la creación original de la serie icónica de los Trastámaras y Habsburgos, habría que buscar posibles antecedentes en la ciudad de Sevilla, donde la familia ostentaba un monumental palacio ${ }^{24}$, en sus alrededores contó con importantes fundaciones, como el monasterio fortificado de San Isidoro del Campo, y desde donde ejerció una parcela esencial de su poder en la región durante la Baja Edad Media, que la condujo a situaciones de conflicto con otras poderosas familias, como los Ponce

${ }^{20}$ CARRIAZO RUBIO, Juan Luis: "La atribución a mosén Diego de Valera del Origen de la Casa de Guzmán", en MOYA GARCÍA, Cristina (ed.): Mosén Diego de Valera. Entre las armas y las letras. Woodbridge, 2014, pp. 179-193.

${ }^{21}$ LADERO QUESADA, Miguel Ảngel: Guzmán. La Casa ducal..., op. cit, pp. 502-503.

22 ÁlVAREZ DE TOLEDO, Luisa Isabel: Alonso Pérez de Guzmán, General de la Invencible. 2 tomos. Cádiz, 1994; y ÁLVAREZ DE TOLEDO, Luisa Isabel: Casa Medina Sidonia. De Juan de Guzmán a Gaspar de Guzmán (1492-1664). Sanlúcar de Barrameda, 2008, pp. 25-26.

${ }^{23}$ Sobre la creación de la imagen literaria y visual de la Casa ducal, véase como síntesis CRUZ ISIDORO, Fernando: "La literatura y la iconografía al servicio de los Guzmanes", en Sanlúcar Señorial y Atlántica. III y IV Jornadas de Investigación del Patrimonio Histórico-Artístico 2013-2014. Sanlúcar de Barrameda, 2016, pp. 63-100.

${ }^{24}$ CRUZ ISIDORO, Fernando: "El palacio sevillano de los Guzmanes según dos planos de mediados del siglo XVII", Laboratorio de Arte, 19, 2006, pp. 247-262. 
de León, que provocaron la intervención de los Reyes Católicos ${ }^{25}$. Lo que conocemos sobre el gusto estético de la familia y, en concreto del VII duque, así nos lo confirma ${ }^{26}$, en buena medida orientado a la monumentalización de la capital de su Estado, la ciudad de Sanlúcar de Barrameda, concebida como una auténtica civitas dei, al seguir un planteamiento urbanístico y constructivo de ciudadconventual ${ }^{27}$.

Referencias cercanas serían la del Alcázar segoviano pero, fundamentalmente, la de reyes y damas del arrocabe de la media naranja dorada del Salón de Embajadores del Alcázar sevillano del rey don Pedro, que se renovó pocos años antes, en 1599, por el pintor Diego de Esquivel que, como hemos comprobado, fue el tasador del cuadro sanluqueño ${ }^{28}$. Y otro punto de contacto sería el que fuese alcaide del Alcázar don Enrique de Guzmán, tío del VII duque. Para estructurar la composición de la serie icónica, el pintor adoptó el habitual esquema de árbol genealógico, como hicieron en Europa e Hispanoamérica algunas órdenes religiosas y otras casas nobiliarias para mostrar la grandeza de sus

${ }^{25}$ LADERO QUESADA, Miguel Ángel: Historia de Sevilla. La ciudad medieval (1248-1492). $3^{\mathrm{a}}$ ed., Sevilla, 1989, p. 137; y COLLANTES DE TERÁN, Antonio: Sevilla en la Baja Edad Media. La ciudad y sus hombres. Sevilla, 1984, pp. 224-226.

${ }^{26}$ CRUZ ISIDORO, Fernando: "La colección pictórica del palacio sanluqueño de la Casa ducal de Medina Sidonia entre los años de 1588 y 1764", Laboratorio de Arte, 16, 2003, pp. 151-169; CRUZ ISIDORO, Fernando: "El mecenazgo arquitectónico de la Casa ducal de Medina Sidonia entre 1559 y 1633”, Laboratorio de Arte, 18, 2005, pp. 173-184; y CRUZ ISIDORO, Fernando: "Aporte documental al mecenazgo artístico de los VII y VIII duques de Medina Sidonia", Sanlúcar de Barrameda, 42, 2006, pp. 126-137.

${ }^{27}$ CRUZ ISIDORO, Fernando: "El Patrimonio Artístico Sanluqueño y los Guzmanes (1297-1645)", en El Río Guadalquivir. Del mar a la marisma, Sanlúcar de Barrameda. T. II. Sevilla, 2011, pp. 161-167; CRUZ ISIDORO, Fernando: "Arte y Arquitectura en la Sanlúcar del Siglo XVI", en Sanlúcar, la Puerta de América. Estudios Históricos y Artísticos. Sanlúcar de Barrameda, 2012, pp. 227-297; y CRUZ ISIDORO, Fernando: "El patronazgo y la corte artística de los Pérez de Guzmán en la Sanlúcar de los siglos XVI y XVII", e-Spania, 2017: http://e-spania.revues.org/26216; DOI: 10.4000/e-spania.26216.

${ }^{28}$ Contrató las 32 pinturas de damas y reinas del arrocabe sobre la galería de arquillos góticos de los reyes, que quizás también tuvo que repintar. CASTILLO OREJA, Miguel Ángel: "Imagen del rey, símbolos de la monarquía y divisas...", op. cit., p. 32. El profesor Alfredo Morales ha hecho notar la superior calidad de esas damas con respecto a los reyes, con mayor dominio técnico y formas avanzadas, con ecos de Sánchez Coello y de los retratistas de la Corte, por lo que baraja la hipótesis de que los retratos de los monarcas debieron ser rehechos en 1624 por su mal estado, cuando se preparó el palacio para la visita de Felipe IV. MORALES MARTÍNEZ, Alfredo: "Memoria de la monarquía hispana. La Galería de Reyes y Damas del Salón de Embajadores”, en Galería de Reyes y Damas del Salón de Embajadores. Obras maestras restauradas. Madrid, 2002, pp. 48-51 y 56. 
miembros ${ }^{29}$, con un tronco del que brotan diversas ramas, similar al del parejo cuadro de altar de la Genealogía de Cristo. Para la serie de santos dominicos, con la que se completa el cuadro, se utilizaron diversos grabados, empleando su imagen convencional y símbolos parlantes, con la fecha de fallecimiento y nombre en latín, logrando pedagógicamente que fuesen reconocidos por los devotos. Problemático debió resultar resolver la fisonomía de los personajes de la familia Guzmán, al no contar apenas con una galería de retratos ni elementos diferenciadores, optando por crear una serie icónica de ocho personajes, siete varones y una dama, con atuendos cortesanos y militares, distinguidos por sus nombres. Para los Trastámaras y Habsburgos, posiblemente Esquivel pudo proporcionarle modelos e ideas, e incluso no sería descabellado pensar, dada su relación, que Juanete hubiese intervenido previamente en el remozamiento que allí se hizo hacia 1599-1600. Pero son especulaciones, aunque no lo es el que este cuadro, de 1612, establezca un elenco de retratos reales que pudo servir de referencia compositiva para la renovación del Alcázar, dada las relaciones familiares de sus alcaides con los señores de Sanlúcar. Siguiendo esas series icónicas, se representa la idea y el concepto de autoridad y prestigio que conllevaba la institución monárquica, con fórmulas convencionales de atuendo y símbolos, como coronas de florones o puntas -al igual que en el Alcázar-, pues la imperial se limitará a Carlos $\mathrm{V}$ y a Maximiliano, a cetros y espadas, empleando la inscripción del nombre para evitar dudas.

La composición arranca del conde de Castilla Rodrigo Núñez, de cuyo hijo, el conde Nuño Rodríguez surgiría, según algunos genealogistas, la línea troncal de los Guzmán. Recostado sobre la tierra y revestido con armadura milanesa semicompleta, de su costado izquierdo surgen las dos ramas que configuran las mitades del árbol genealógico, intentando mostrar cómo la familia fue origen de dos instituciones vitales para el Estado español. Se representan 39 dominicos y 28 laicos ilustres, organizados en ocho filas, más o menos horizontales, que conviven en tan corto escenario al disponerlos de medio cuerpo sobre un fondo neutro turquesa, cerrando los huecos ramas con hojas de roble, de parra y racimos de uva negra. Remata la composición una dominica Virgen del Rosario con el Niño, que refrenda a los representados, pues entrega el rosario a los frailes y la espada y la corona a los laicos.

${ }^{29}$ Como el Stammbaum o árbol que los dominicos veneraban en el retablo mayor de su iglesia de Frankfurt, hoy en el Instituto Staedel de la ciudad, de Hans Holbein el Viejo, o el tríptico con el árbol genealógico de la familia Babenber, que gobernó el ducado austríaco antes de los Habsburgos, obra de Hans Part, hacia 1489-1492, del Museo de la Abadía de Klossterneuburg. RÉAU, Louis: Iconografía del arte cristiano. Iconografía de la Biblia. Nuevo Testamento. T. I, vol. II. Barcelona, 1997, pp. 141-142; y MALO LARA, Lina: "Conflictos de poder...", op. cit, p. 103, nota 25. 
Los dominicos arrancan con Félix de Guzmán, padre del venerable Antonio, del beato Manés y de Santo Domingo de Guzmán, representados a continuación. Siguen San Vicente Ferrer, San Raimundo de Peñafort, San Pedro de Verona, un santo sin identificar, Santa Catalina de Siena, San Antonino de Florencia, Santo Tomás de Aquino, el Beato Jacobo Bianconi de Mevania, quizás San Juan de Colonia, el inquisidor Fray Conrado de Alemania de Grosis, Jacobo de Como, el Beato Ambrosio Sansedonio de Siena, los Seis mártires de Tolosa, los Beatos Enrique Susó, Francisco Mártir y Jacobo Salomón, Santa Inés de Montepulciano, San Pedro González Telmo, los venerables Jerónimo Cala y Vicente de San Esteban, San Jacinto Beltrán, Santa Margarita de Hungría, los beatos Cristiano, Patriarca de Antioquía, y Juan Teutónico, San Alberto Magno de Colonia, los beatos Juan Dominici, Juan Garbella de Vercelli y otro sin identificar y, finalmente, los pontífices Benedicto XI, Inocencio $V$ y San Pío $V$.

En el lado derecho los seglares de la familia. En la primera de las ramas Álvaro Rodríguez Guzmán, Pedro Ruiz Guzmán y, con atuendo militar, Guillermo Pérez Guzmán y Pedro Núñez Guzmán. En la segunda Alvar Pérez de Guzmán y Alfonso y su hijo Pedro Núñez de Guzmán y Girón. La presencia de ese último es clave, por ser el progenitor de la que podemos considerar, en esencia, la protagonista del cuadro, Leonor Núñez de Guzmán, señora de Medina Sidonia, Cabra, Oropesa y Paredes de Nava, que fue amante del rey castellano Alfonso XI el Justiciero (13121350), y el entronque del linaje con la Casa Real. De ahí que se les represente juntos, como pareja de hecho, entrelazando fielmente sus manos y con el ademán de entregarle el rey la corona a la dama (Figura 2). Parece que la conoció cuando recaló en Sevilla en la primavera de 1331, y quedó prendado de su belleza, descrita como apuesta y fina, y mantuvo con ella una estrecha unión extramatrimonial de por vida, frente a su desairada esposa María de Portugal y el legítimo heredero, el futuro Pedro I el Justiciero, que le guardarían especial inquina, hasta ser ajusticiada en la cárcel de Talavera de la Reina en 1351. Tuvieron varios bastardos, a los que el padre dotó como si fueran príncipes. Por tanto, no extraña que todos los anteriores miembros de la familia que aparecen en el árbol hayan sido elegidos para conducirnos hasta ese punto de inflexión, vital para el linaje. El pintor no duda en esmerarse en su representación, quizás empleando como modelo alguna de las hijas del VII duque o a su difunta esposa Ana de Silva ${ }^{30}$.

De ahí que la tercera banda se inicie con el fruto de esa unión, el monarca Enrique II (1369-1379), que inicia la nueva dinastía de los Trastámaras castellanos, al que siguen su hijo Juan I (1379-1390), representado joven e imberbe, casado con Leonor de Aragón, origen de una nueva rama gobernante, pues si su hijo Enrique III el Doliente (1390-1406) lo hará en Castilla, Fernando I el de Antequera (1412-1416) será el primer monarca Trastámara de Aragón (Figura 3). A partir

${ }^{30}$ GARCÍA CARRAFFA, Alberto y Arturo: Diccionario Heráldico y Genealógico de apellidos españoles y americanos. T. 40. Salamanca, 1931, pp. 174-175. 
de aquí el árbol se articulará en dos ramas que, tras un breve recorrido, terminarán uniéndose de nuevo. De Enrique III partirá el ramal de su hijo Juan II (14061454), que devendrá en otra figura clave, la reina Isabel la Católica (1474-1504), que aquí tiene más valor si cabe, al no estar representada en la serie del Alcázar sevillano (Figura 4). El otro brazo, el de Fernando I, devengará en Juan II (14581479), rey de Navarra y de Aragón (Figura 5), y dará lugar a la figura de Fernando II el Católico (1479-1516), soberano aragonés y de Castilla por su unión con Isabel. A partir de ellos, las brozas se unirán en la reina Juana (1479-1555), que también falta en la serie hispalense y nuevo nudo, pues dos serán las cepas que de ella surjan. Por un lado la dinastía gobernante en España, representada por su hijo Carlos I (1500-1558 $)^{31}$, que también lo será del imperio alemán, de ahí su atuendo militar, con coraza y espada, orbe y la corona imperial. Le brotarán su hijo $\mathrm{Fe}$ lipe II (1527-1598) y su nieto Felipe III (1578-1621), que reina cuando se pinta el cuadro (Figura 6).

La otra rama que parte de la reina Juana dirigirá el imperio germano, con su hijo Fernando I (1503-1564), archiduque de Austria y rey de Hungría y Bohemia, casado con Ana de Bohemia, al que su hermano Carlos eligió como heredero. Ambos son efigiados con manto de armiño, espada, orbe y corona imperial. De su nieta María de España, hija de Carlos I y esposa del emperador Maximiliano II (1527-1576), presente en el cuadro, procederá la estirpe que seguirá rigiendo buena parte de Europa. De él partirán las ramas que conduzcan al archiduque Matías (1557-1619), que llegó a emperador; la del emperador Rodolfo II (15521612) y la del duque de Brabante Alberto (1559-1621), archiduque de Austria, todos educados en la corte hispana de Felipe II. No queda clara la presencia de un Maximiliano, con atuendo militar. Alberto, que escogió al principio la senda religiosa, pasaría a gobernar Portugal y los Países Bajos al casar con su tía Isabel Clara Eugenia (1566-1633), condesa de Flandes y duquesa de Brabante, hija de Felipe II y de Isabel de Valois, que culmina el árbol (Figura 7).

La iconografía del cuadro se completa, en el banco, con tres escenas histórico-míticas que se escogen de la biografía novelada del fundador del linaje don Alonso Pérez de Guzmán el Bueno, que son el aval de la inquebrantable lealtad de la familia a la Casa Real: la heroica defensa de Tarifa, el degollamiento de Pedro Alfonso y la lucha de Guzmán el Bueno con la serpiente-dragón de Fez. El cuadro de altar continúa en la iglesia, aunque desplazado desde 1835 a la segunda capilla del muro de la epístola.

Fecha de recepción: 5 de octubre de 2017

Fecha de aceptación: 12 de abril de 2018

31 VV.AA.: Carolus V Imperator. Lunwerg, 1999. 


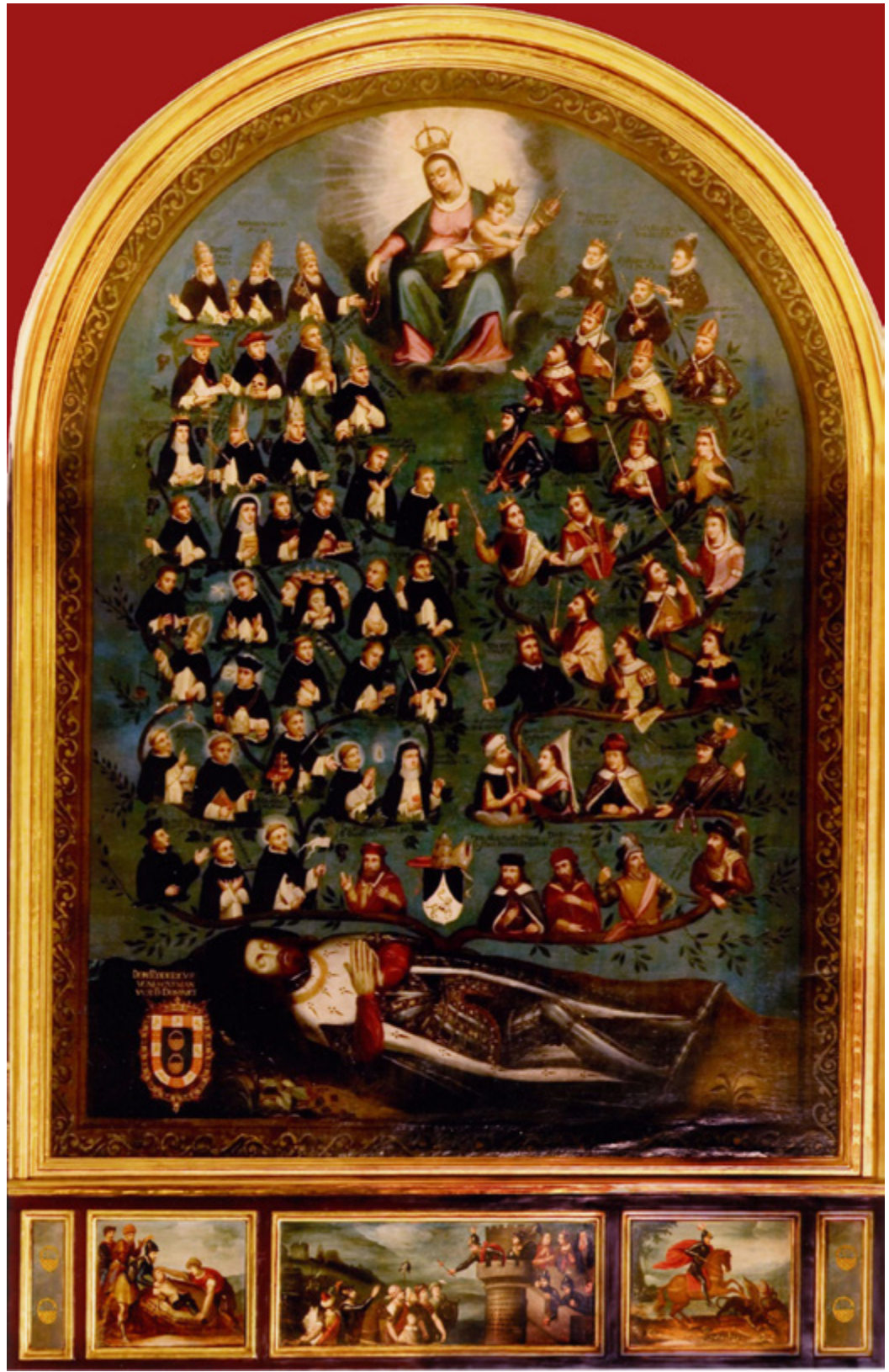

Figura 1. Francisco Juanete, Genealogía de los Guzmanes, 1612, basílica menor de Nuestra Señora de la Caridad, Sanlúcar de Barrameda. Foto: Fernando Cruz. 


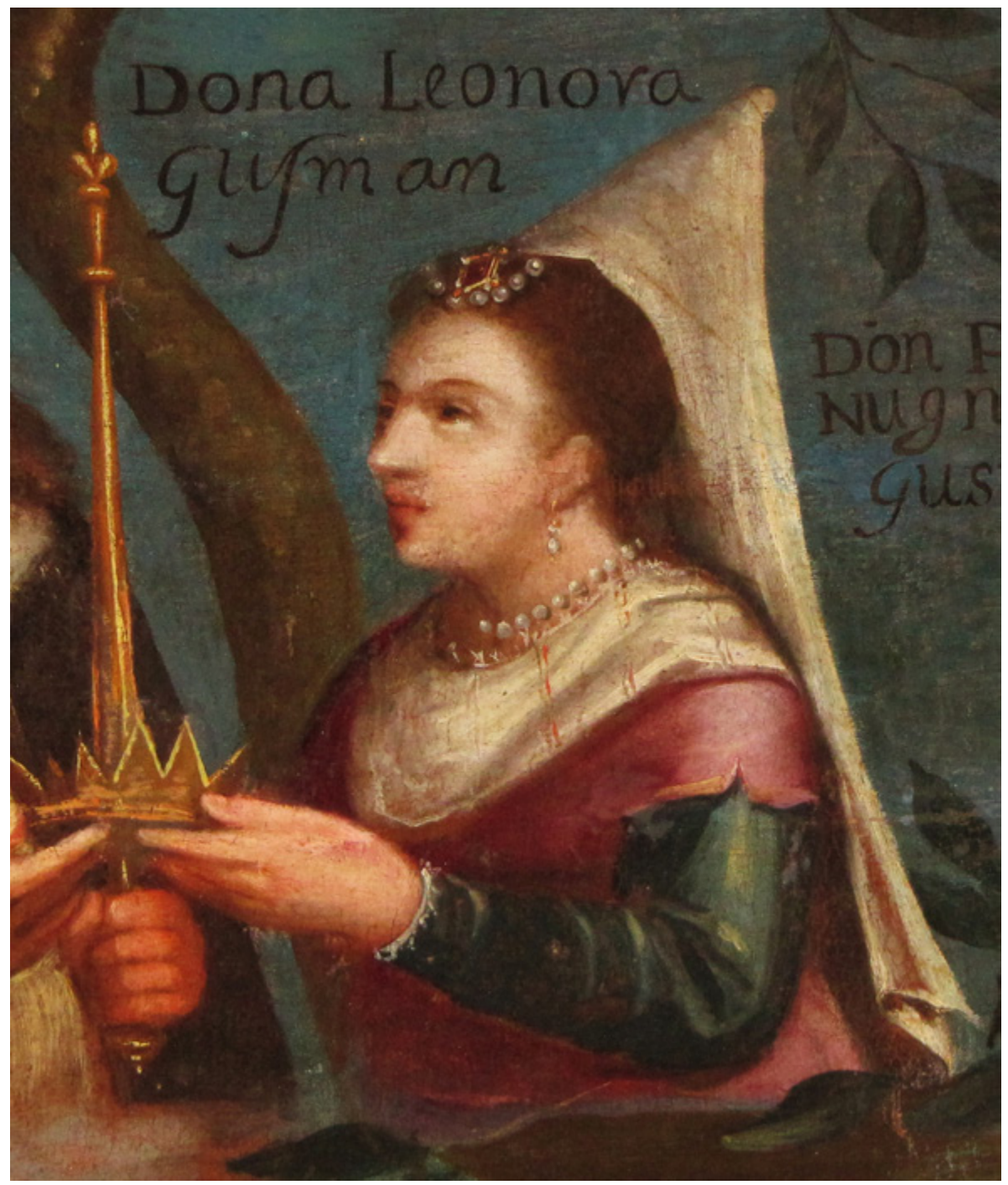

Figura 2. Francisco Juanete, Genealogía de los Guzmanes (Doña Leonor de Guzmán), 1612, basílica menor de Nuestra Señora de la Caridad, Sanlúcar de Barrameda. Foto: Fernando Cruz. 


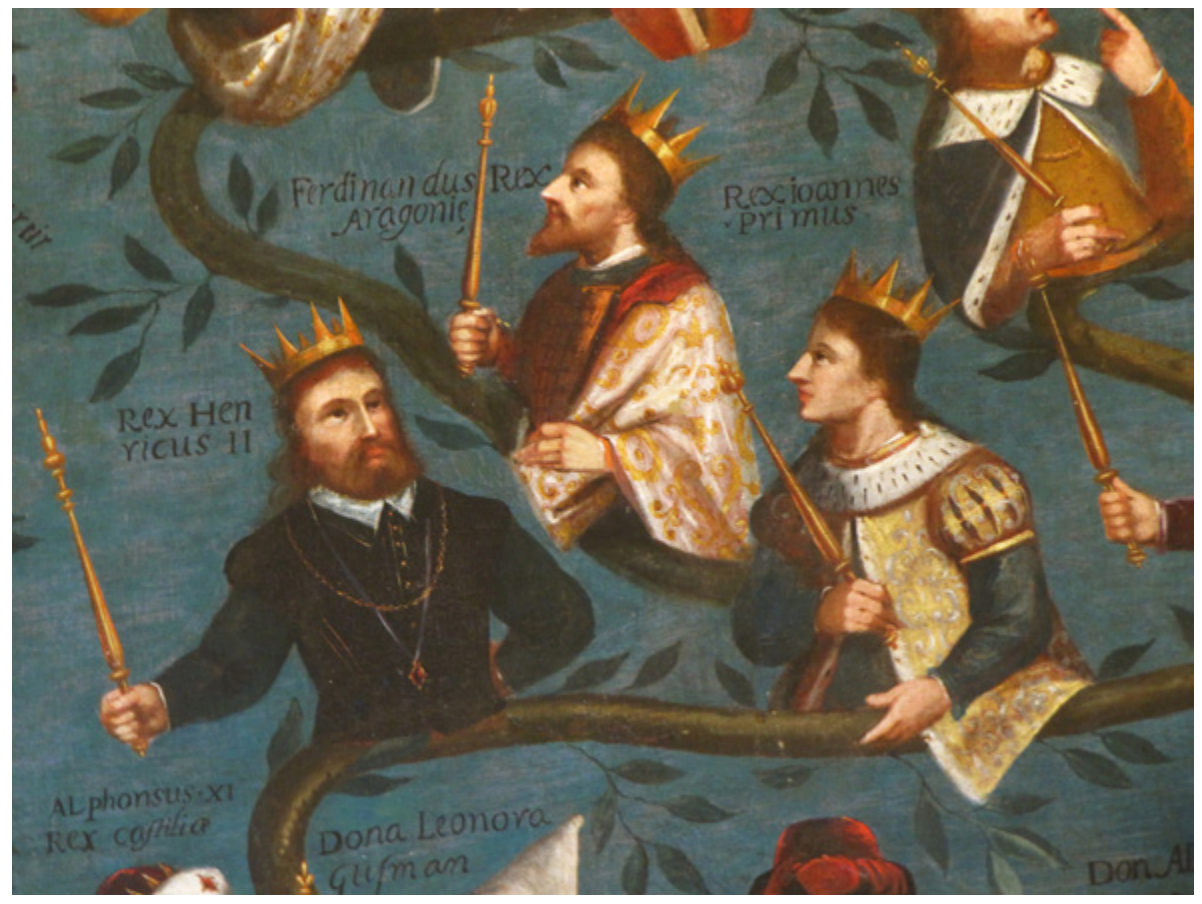

Figura 3. Francisco Juanete, Genealogía de los Guzmanes (Enrique II, Juan I y Enrique III el Doliente), 1612, basílica menor de Nuestra Señora de la Caridad, Sanlúcar de Barrameda. Foto: Fernando Cruz. 


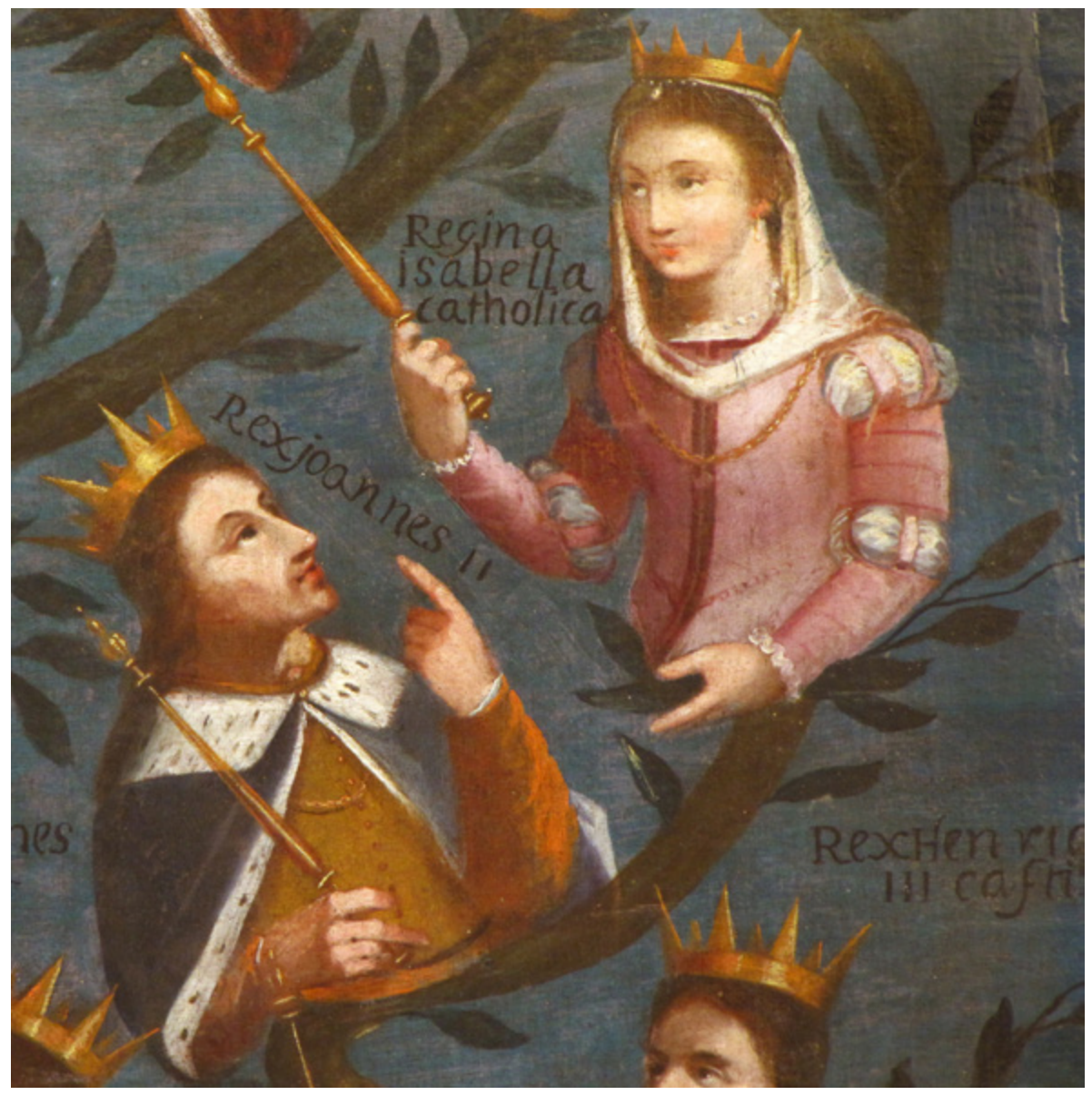

Figura 4. Francisco Juanete, Genealogía de los Guzmanes (Juan II e Isabel la Católica), 1612, basílica menor de Nuestra Señora de la Caridad, Sanlúcar de Barrameda. Foto: Fernando Cruz. 


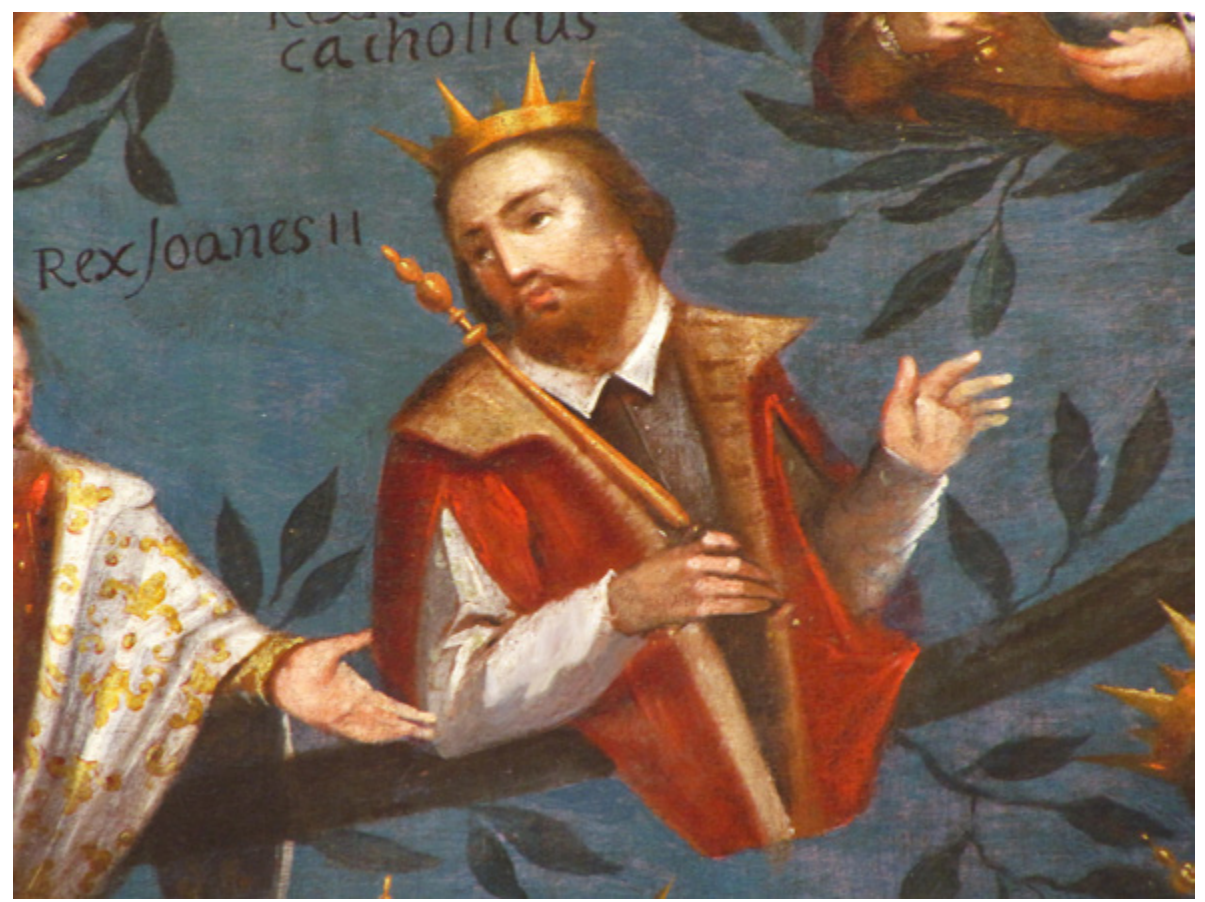

Figura 5. Francisco Juanete, Genealogía de los Guzmanes (Juan II), 1612, basílica menor de Nuestra Señora de la Caridad, Sanlúcar de Barrameda. Foto: Fernando Cruz. 


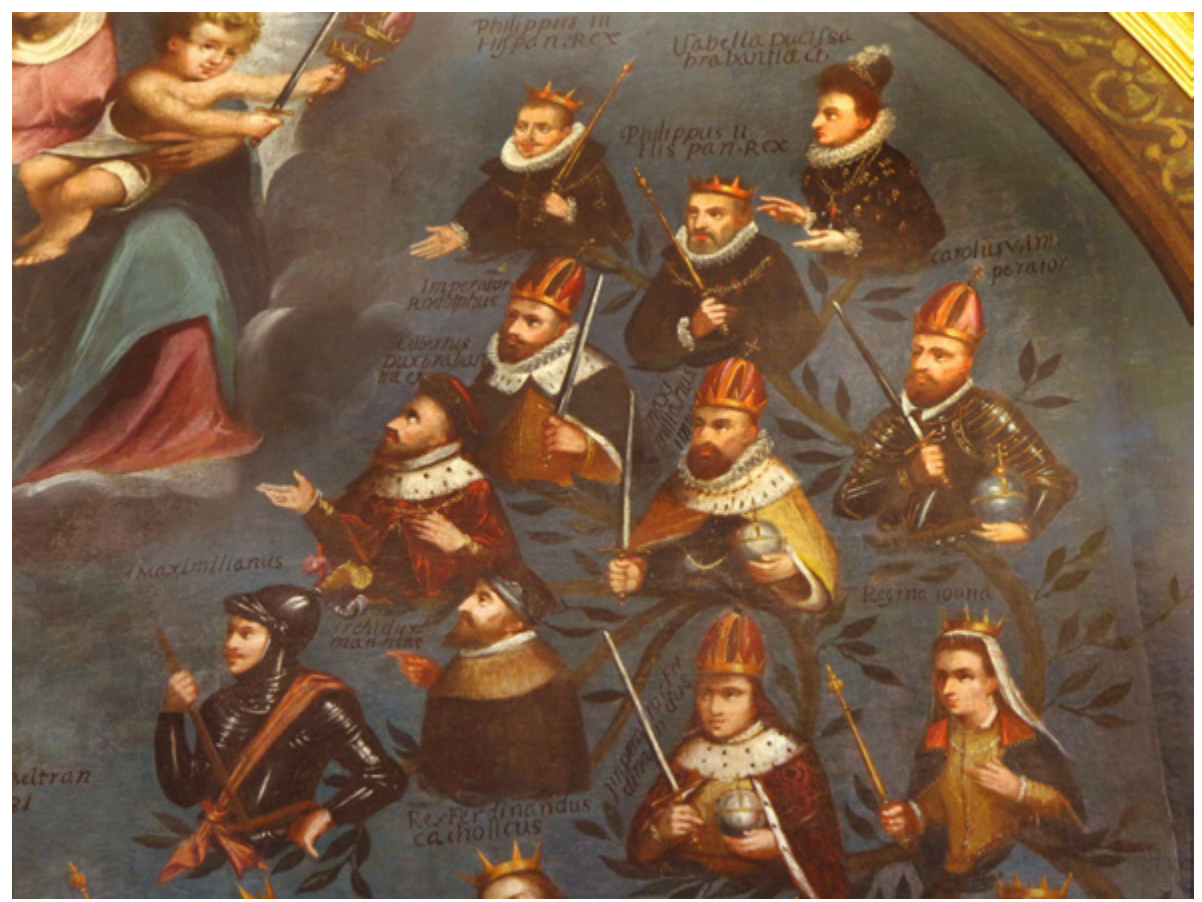

Figura 6. Francisco Juanete, Genealogía de los Guzmanes (Juana la Loca y otros), 1612, basílica menor de Nuestra Señora de la Caridad, Sanlúcar de Barrameda. Foto: Fernando Cruz. 


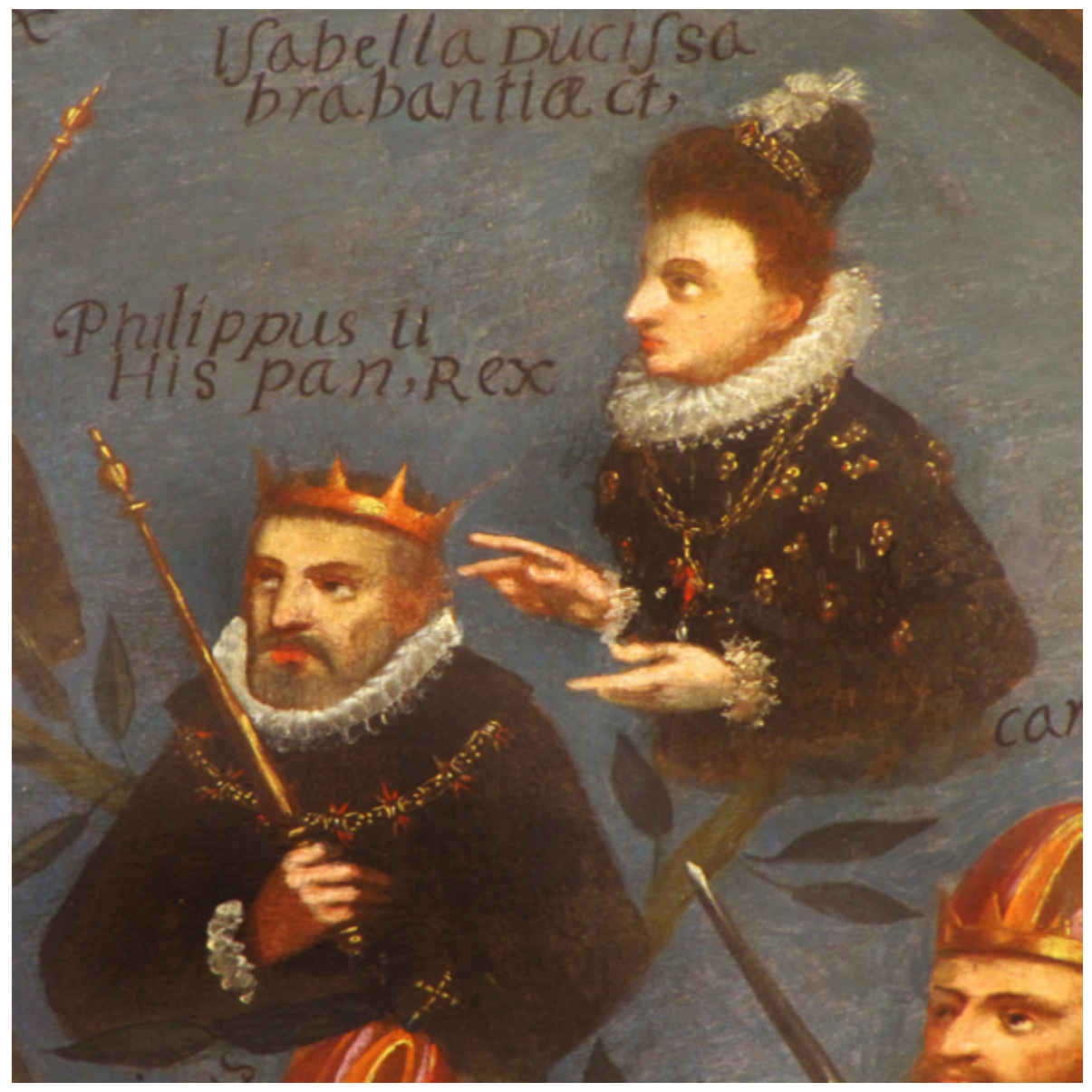

Figura 7. Francisco Juanete, Genealogía de los Guzmanes (Felipe II e Isabel Clara Eugenia), 1612, basílica menor de Nuestra Señora de la Caridad, Sanlúcar de Barrameda. Foto: Fernando Cruz. 